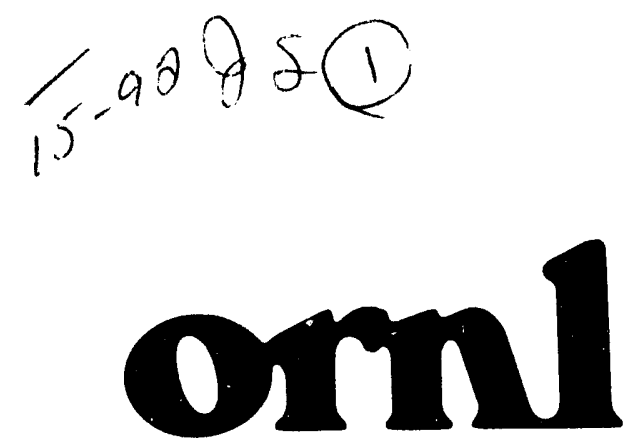

OAK RIDGE NATIONAL LABORATORY

MARTIN MARTETRA
ORNL/TM-11995
Office of Radiation Protection

\section{Background Radiation}

Accumulation and Lower Limit of Detection in Thermoluminescent Beta-Gamma Dosimeters Used by the Centralized External Dosimetry System
E. Sonder

A.B. Ahmed 
This report has been reproduced directly from the best available copy.

Available to DOE and DOE contractors from the Office of Scientific and Technical Information, P.O. Box 62, Oak Ridge, TN 37831; prices available from (615) 576-8401, FTS 626-8401.

Available to the public from the National Technical information Service, U.S. Department of Commerce, 5285 Port Royal Rd., Springfield, VA 22161.

This report was prepared as an account of work sponsored by an agency of the United States Government. Neither the United States Government nor any agency thereof, nor any of their employees, makes any warranty, express or implied, or assumes any legal liability or responsibility for the accuracy, completeness, or usefulness of any information, apparatus, product, or process disclosed, or represents that its use would not infringe privately owned rights. Reference herein to any specitic commercial product, process, or service by trade name, trademark, manufacturer, or otherwise, does not necessarily constitute or imply its endorsement, recommendation, or favoring by the United States Government or any agency thereof. The views and opinions of authors expressed herein do not necessarily state or reflect those of the United States Government or any agency thereof. 
ORNL/TM--11995

DE92 005027

Office of Radiation Protection

\title{
BACKGROUND RADIATION ACCUMULATION AND LOWER LIMIT OF DETECTION IN THERMOLUMINESCENT BETA-GAMMA DOSIMETERS USED BY THE CENTRALIZED EXTERNAL DOSIMETRY SYSTEM
}

\author{
E. Sonder \\ A.B. Ahmed \\ Date Published - December 1991 \\ Prepared for the Office of Environment, Safety, and Health \\ Prepared by \\ OAK RIDGE NATIONAL LABORATORY \\ Oak Ridge, Tennessee, 37831 \\ managed by \\ MARTIN MARIETTA ENERGY SYSTEMS, INC. \\ for the \\ U.S. DEPARTMENT OF ENERGY \\ under Contract No. DE-AC05-84OR21400
}




\section{CONTENTS}

Page

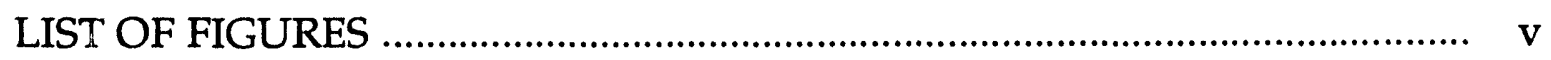

LIST OF TABLES …................................................................................... vii

ABSTRACT …

1. INTRODUCTION ……………………………...................................... 1

2. OUTLINE OF EXPERIMENTS.............................................................. 2

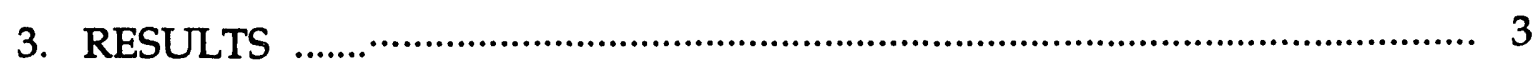

3.1 Direct Measurement of Threshold Signals ...................................... 3

3.2 Background Radiation Accumulation During Extended Periods .................................................................................. 4

3.3 Determination of Do for Routine Dosimeter Use …………......... 7

3.4 Variation of Background Radiation …………….............................. 7

3.5 Lower Limit of Detection .................................................................... 11

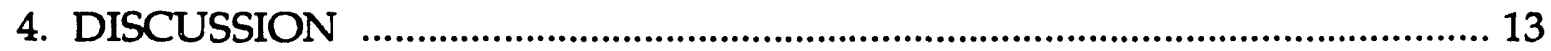

4.1 High Do Values for Chip 3 ................................................................. 13

4.2 Possible Difference in Background Accumulation of the Four Chips ............................................................................. 13

4.3 Reason for High $L_{D}$ in Dosimeters Stored for Extended Times .. 14

4.4 Lower Limit of Detection to be Used for Personnel Dosimeters . 14

$4.5 \mathrm{~L}_{\mathrm{D}}$ Values for Beta Spectra 15

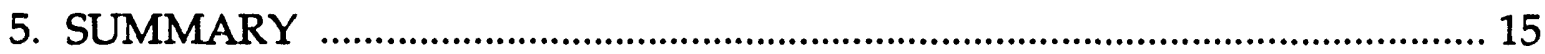

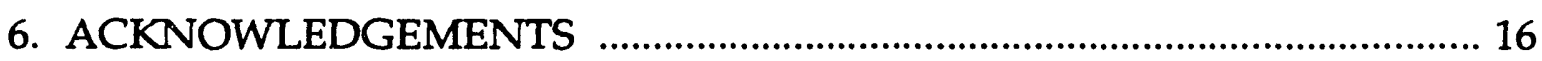

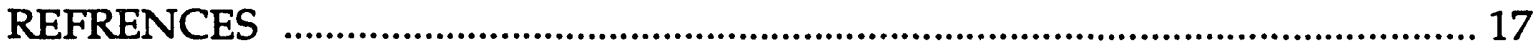




\section{LIST OF FIGURES}

Figure

Page

1: Average Dosimeter Response for Different Exposure Times. Only reader correction factors and element correction coefficients have been applied; no residual signal has been subtracted. The numbers given on the figures are calculated intercepts $\left(\mathrm{y}_{\mathrm{o}}\right)$ and slopes $(\mathrm{m})$ for linear fits to the data. (a) data and fit for Chip 1;

(b) Chip 2; (c) Chip 3; (d) Chip 4

2: Average Residual Response of Encased Dosimeters stored in Room Light. The contribution of actual background gamma radiation $(.75 \mathrm{mR} /$ week) has been subtracted from all points. The curves shown are drawn simply to indicate data sets for the different chips. Data for chips 1 and 4 are similar so that they are indicated by the same curve. For chip \#3 the ordinate scale on the right should be used

3: Distribution of Background Dose Rates as Measured at Many Location Over Periods of Approximately Five Months. Data from Chips 1 and 2 are recorded. Threshold values of $3 \mathrm{mR}$ have been subtracted from the measured reader response. The parameters shown have been obtained from a Least Squares fit of the data to the equation as shown in the inset

4: Average Dosimeter Response Measured Each Month During One Year. Month \# 1 refers to May 1990 and Month \# 12 refers to April , 1991. The error bars at the right of the figures are standard errors calculated from data from approximately 60 to 70 locations 


\section{LIST OF TABLES}

Table

Page

1. Threshold Signal of Annealed Dosimeters Kept in Darkness .... 3

2. Best Fit Parameters from Cumulative Dosimeter Averages ...... 4

3. Lower Limit of Detection ................................................................... 12 


\begin{abstract}
A value for "average background radiation" of $0.75 \mathrm{mR} /$ week has been determined from a total of 1680 thermoluminescent dosimeters (TLD's) exposed in 70 houses for periods up to one year. The distribution of results indicates a rather large variation among houses, with a few locations exhibiting backgrounds double the general average. Some discrepancies in the short-term background accumulation of TLD's have been explained as being due to light leakage through the dosimeter cases. In addition the lower limit of detection ( $L_{D}$ ) for deep and shallow dose equivilents has been determined for these dosimeters. The $L_{D}$ for occupational exposure depends strongly on the time a dosimeter is exposed to background radiation in the field. The $L_{D}$ can vary from a low of 2.4 mrem for high energy gamma rays when the background accumulation period is less than a few weeks to values as high as 66 mrem for uranium beta particles when background has been allowed to accumulate for more than 21 weeks.
\end{abstract}




\section{INTRODUCTION}

It is common practice in personnel dosimetry to subtract background radiation from dosimeter readings and to record the difference, i.e., the "occupational exposure". In many situations the value to be subtracted can be measured by placing a number of "control dosimeters" at the location where all personnel dosimeters are stored at the end of a working day. These control dosimeters are processed together with other personnel dosimeters at the end of the wearing period. Subtraction of their average dose accumulation from the total personnel doses yields vaiues for occupational exposures; the uncertainties of these depend mainly on the accuracy and precision of the personnel and control dosimeters. The above method cannot be applied at Martin Marietta Energy Systems facilities due to the fact that dosimeters are attached to the employees' security badges and are taken home at the end of a working day. Also, although the typical dosimeter assignment period is three months, dosimeters are frequently processed after wearing periods from a few weeks to six months. Since the background dose accumulation of thermoluminescent dosimeters(TLD's) depends on location and time, it is necessary to measure this accumulation for different times at a large number of locations. For the present study 24 dosimeters ${ }^{1}$, exposed for times between 5 weeks and one year, in each of 70 locations (a total of 1680 dosimeters) were analyzed.

The background radiation has been measured previously 2 . In that study three sets of 22 dosimeters were measured after background exposure of 5, 10, and 14 weeks in homes in the vicinity of Oak Ridge. An average value of 1.05 $\mathrm{mR} /$ week was obtained. However the experiments were not designed to determine non-linearities in dosimeter response to long-time ( $>3$ months) background irradiation; nor were they designed to assess variations due to season or location. The data obtained in the present study are analyzed to determine the dosimeter response to both short and long time background irradiation and to determine whether there exist any seasonal or locational variations. In addition some discrepancies in very low dose responses are resolved and the lower limit of detection ${ }^{3}\left(L_{D}\right)$ is calculated for gamma ray or beta particle irradiated dosimeters. 


\section{OUTLINE OF EXPERIMENTS}

The background that is subtracted from measured TL signals to determine occupational exposures consists of two parts. We will define these as the "threshold" response, which includes instrument noise and light emission due to effects other than radiation, and "natural background" that is due to radiation and increases with time.

The "threshold" signal was measured directly for various times less than $\sim 20$ days after annealing of the dosimeters. As many as 150 TLD cards were used and averaged for some of these measurements. Because the Teflon used to hold the LiF chips has been shown ${ }^{4}$ to emit light after room or sun light illumination, many of these cards were kept from room light exposure between repeated readouts; others were encased in holders and stored in normal room light. Values for the threshold were also determined by extrapolation of cumulative background dose measurements to zero time. As will be discussed below, different values were obtained from the cards kept in the dark as from those placed in holders and stored in light.

The "natural background" dose rate and its variation were determined by placing TLD's in 70 different homes, 50 in the Oak Ridge-Knoxville area and 20 in the vicinity of Paducah, KY. The dosimeters were accompanied by a set of instructions, to prevent storage of the dosimeters near radiation sources, heat or intense light. "Cumulative" and "monthly" measurements were made over a period of one year. For the cumulative measurements, 12 annealed dosimeters were put in place at the beginning of the experiment ( 1 May 1990); one of these was measured after each month. For the monthly measurements, dosimeters were annealed and exchanged every month at each location. The total time between anneal and measurement for each month was between 5 and 6 weeks.

Values of the lower limit of detection $\left(L_{D}\right)$ were determined according to procedures prescribed in the Department of Energy Standard for the Performance Testing of Personnel Dosimetry Systems ${ }^{3}$. A total of 10 values of the $L_{D}$ were determined. There were five exposure categories, deep dose for ${ }^{137} \mathrm{Cs}$ gamma rays, and shallow dose due, respectively, to ${ }^{137} \mathrm{Cs}, 90 \mathrm{Sr} / \mathrm{Y},{ }^{204} \mathrm{Tl}$, and depleted uranium beta-particles. For each of these exposure categories the dosimeters received additional 6.5 or 23 weeks of background gamma irradiation by being stored in homes in which the background dosimeters were also located. The 23 week time corresponds approximately to the time between anneal and readout of quarterly personnel dosimeters. Each value of $L_{D}$ was obtained from measurements of ten irradiated dosimeters stored in different homes and from approximately 50 unirradiatied dosimeters stored for comparable time. 


\section{RESULTS}

\section{1: Direct Measurement of the Threshold Signal.}

The total response of approximately 380 unirradiated dosimeters, kept in darkness is summarized in Table I. The signal shown is in generic reader units, gU. A gU is approximately equal to a $\mathrm{mR}$ for ${ }^{137} \mathrm{Cs}$ gamma rays; to simplify $m R$ will be used in this report to indicate $g U$. Element correction factors have been included. Also shown in this table are standard deviations (SD) of the measurements making up the given averages.

TABLE I: Threshold Signal of Annealed Dosimeters Kept in Darkness.

\begin{tabular}{|c|c|c|c|c|c|}
\hline $\begin{array}{l}\text { Time after } \\
\text { anneal } \\
\text { (h) }\end{array}$ & $\begin{array}{l}\text { Number of } \\
\text { dosimeters }\end{array}$ & chip 1 & $\begin{array}{l}\text { Averag } \\
\text { Standa } \\
\text { chip } 2\end{array}$ & $\begin{array}{l}\text { Signal and } \\
\text { Deviation } \\
\text { chip } 3\end{array}$ & chip 4 \\
\hline 1.7 & 48 & $\begin{array}{r}.89 \\
\pm .18\end{array}$ & $\begin{array}{r}.76 \\
\pm .19\end{array}$ & $\begin{array}{r}8.77 \\
\pm 3.21\end{array}$ & $\begin{array}{r}1.61 \\
\pm .58\end{array}$ \\
\hline 2.8 & 48 & $\begin{array}{r}.86 \\
\pm .24\end{array}$ & $\begin{array}{r}.80 \\
\pm .28\end{array}$ & $\begin{array}{r}9.52 \\
\pm 4.09\end{array}$ & $\begin{array}{r}1.18 \\
\pm .45\end{array}$ \\
\hline 5.8 & 48 & $\begin{array}{r}.97 \\
\pm .20\end{array}$ & $\begin{array}{r}.87 \\
\pm .24\end{array}$ & $\begin{array}{r}9.56 \\
\pm 3.38\end{array}$ & $\begin{array}{r}1.50 \\
\pm .42\end{array}$ \\
\hline 16.0 & 143 & $\begin{array}{r}.98 \\
\pm .22\end{array}$ & $\begin{array}{r}1.08 \\
\pm .23\end{array}$ & $\begin{array}{r}9.55 \\
\pm 2.83\end{array}$ & $\begin{array}{r}1.47 \\
\pm .46\end{array}$ \\
\hline 17.8 & 48 & $\begin{array}{r}1.21 \\
\pm .23\end{array}$ & $\begin{array}{r}1.14 \\
\pm .32\end{array}$ & $\begin{array}{r}9.88 \\
+3.28\end{array}$ & $\begin{array}{r}1.62 \\
\pm .38\end{array}$ \\
\hline 23.0 & 48 & $\begin{array}{r}1.07 \\
\pm .21\end{array}$ & $\begin{array}{r}1.01 \\
\pm .32\end{array}$ & $\begin{array}{r}9.24 \\
\pm 3.20\end{array}$ & $\begin{array}{r}1.54 \\
\pm \quad .43\end{array}$ \\
\hline
\end{tabular}

The data in Table I have large SDs; however a slight increase in signal intensity with storage time can be discerned. Such an increase is exactly what one would expect since the dosimeters are irradiated with background 
radiation during storage. If a value of $0.75 \mathrm{mR} /$ week for background radiation is assumed, (see later sections of this report) 5 the data of Table I can be fitted with linear functions, yielding intercepts for zero time (Do(dark)) of 0.95, $0.89,9.4$, and 1.4, respectively, for Chips 1-4.

\section{2: Background Radiation Accumulation During Extended Periods.}

In Fig. 1 are shown the responses of the "cumulative" background dosimeters, averaged over the 70 home locations, as a function of exposure time. Data for the four chips in a dosimeter card ${ }^{1}$ are depicted separately in Figs. 1a to $1 \mathrm{~d}$. The lines drawn through the poinis are (linear) fits to the data; slopes and intercepts are given on the graphs.

We have also calculated quadratic (see Table II) and exponential fits to the data; these fits were not significantly better than the linear ones shown in Fig. 1. Thus the average background radiation accumulation rates given in Table II for linear fits may be considered constant for times up to at least one year.

TABLE II: Best Fit Parameters from Cumulative Dosimeter Averages

\begin{tabular}{lccc}
\hline & CHIP \# & $\begin{array}{c}\text { INTERCEPT } \\
(\mathrm{mR})\end{array}$ & $\begin{array}{c}\text { SLOPE } \\
\text { (mR/week) }\end{array}$ \\
& 1 & 3.12 & .74 \\
& 2 & 3.05 & .74 \\
LINEAR & 3 & 12.23 & .81 \\
FIT & 4 & 3.84 & .90 \\
& & & \\
& 1 & 2.51 & $.80^{*}$ \\
QUADRATIC & 2 & 2.63 & $.78^{*}$ \\
FIT & 3 & 12.41 & $.78^{*}$ \\
& 4 & 3.88 & $.89^{*}$ \\
\hline
\end{tabular}

* Coefficient of Linear Term 

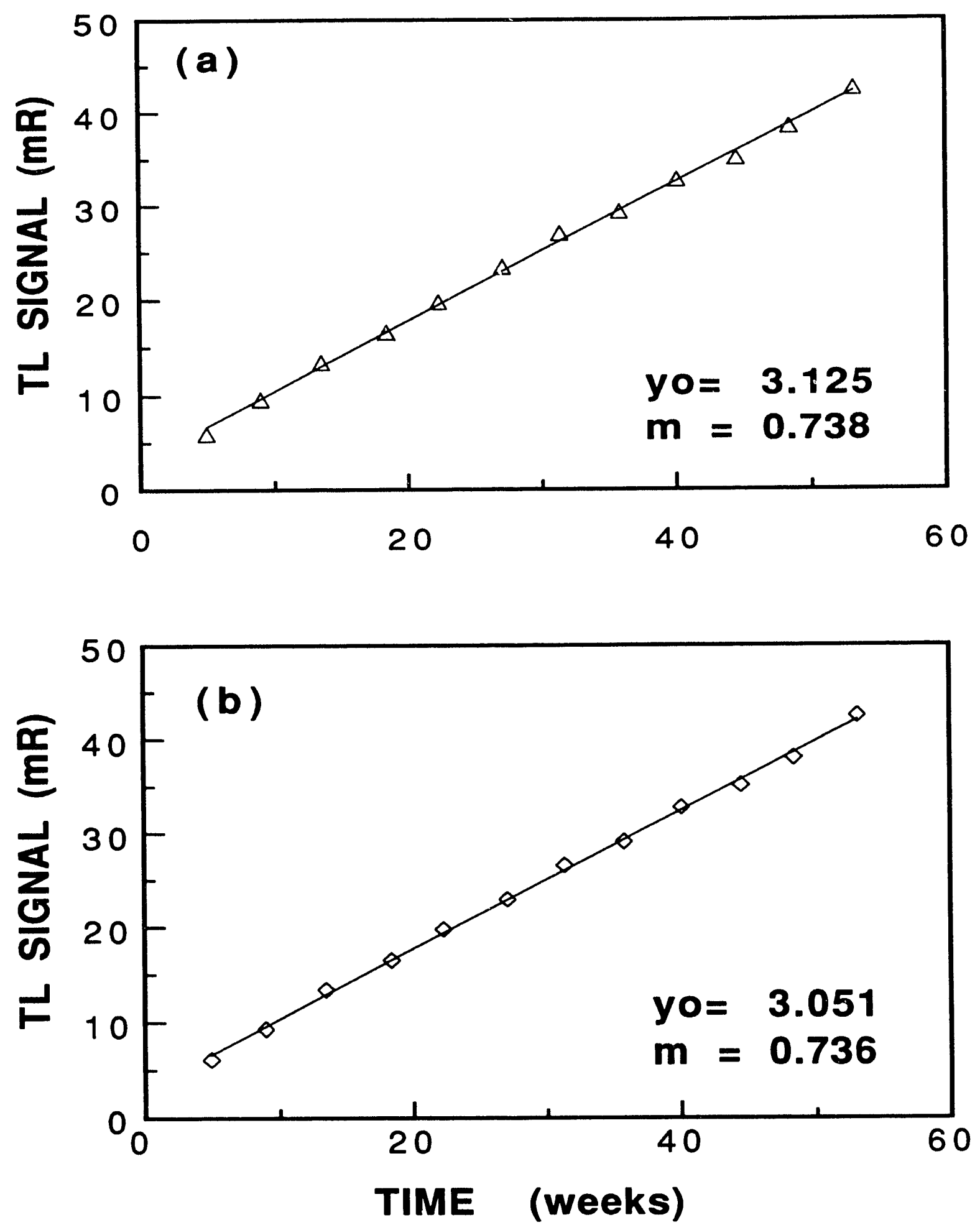

Fig. $1(a, b)$ Average Dosimeter Response for Different Exposure Times. Only reader correction factors and element correction coefficients have been applied; no residual signal has been subtracted. The numbers given on the figures are calculated intercepts (yo) and slopes $(m)$ for linear fits to the data. (a) data and fit for Chip 1;

(b) Chip 2. 

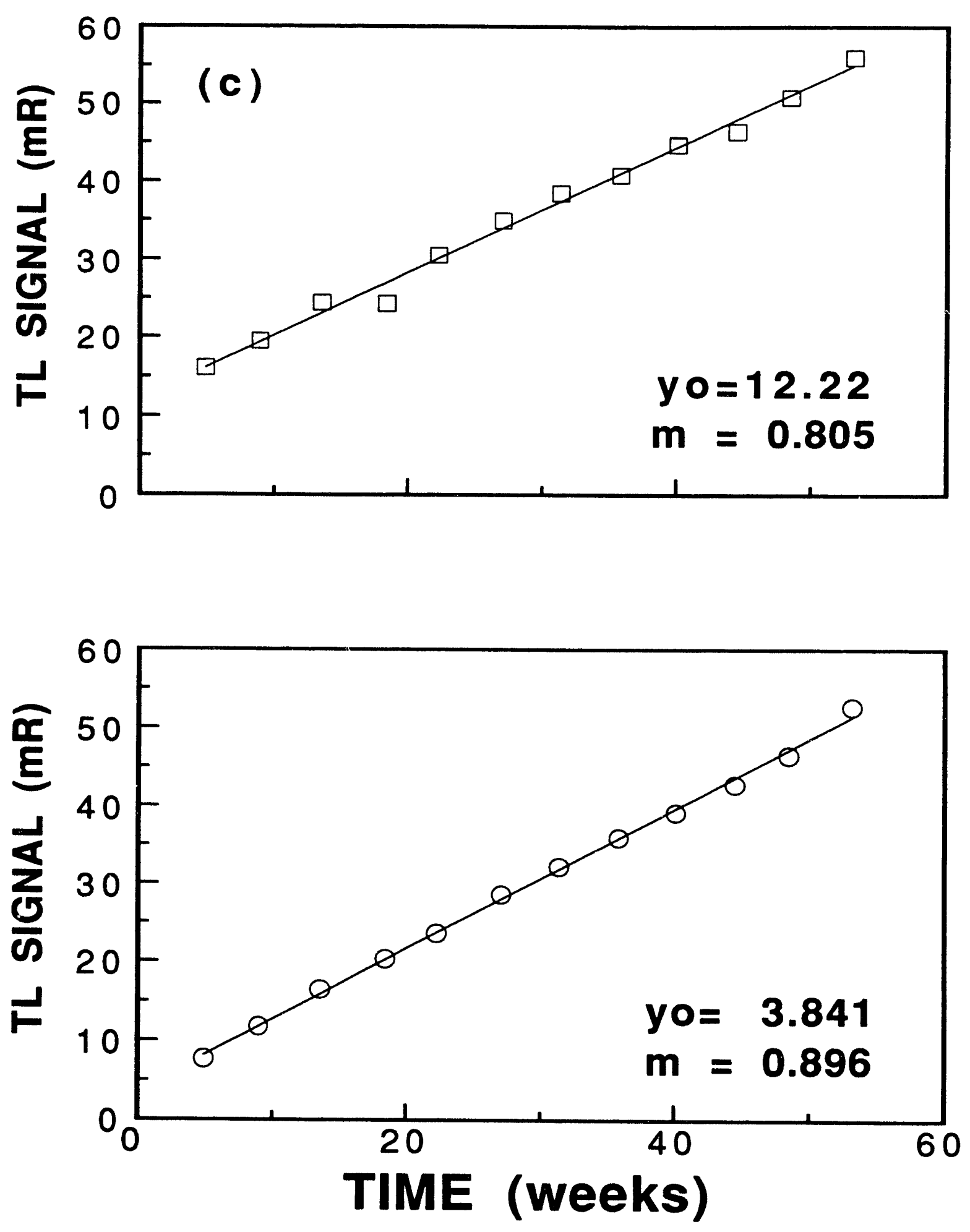

Fig. 1 (c,d) Average Dosimeter Response for Different Exposure Times. Only reader correction factors and element correction coefficients have been applied; no residual signal has been subtracted. The numbers given on the figures are calculated intercepts (yo) and slopes $(m)$ for linear fits to the data. (c) data and fit for Chip 3; (d) Chip 4. 


\section{5: Determination of Do for Routine Dosimeter Use.}

We expected the intercepts of Fig. 1 to be comparable to the measured threshold responses given in Table I. This was not the case as comparison of the Do(dark) values of Section 3.1 and the Intercepts of Table II show. In order to ascertain whether this discrepancy was due to a non-linear response of the dosimeters to low-dose irradiation during storage in the dark we performed additional measurements such as those described in section 3.1 for times up to $400 \mathrm{~h}$. These measurements clearly showed that the dosimeters yielded Do(dark) values as given in Section 3.1 plus a linear increase in dose consistent with the slopes given in Tabie II.

We know from previous work ${ }^{4}$ that incandescent light affects the dosimeter response and that there is some light leakage through the dosimeter holders. Therefore we performed measurements of Do with the dosimeter cards encased in holders, and exposed thus to room light for different times. In Fig. 2 we have plotted the residual signal, Do (after subtracting a radiation background contribution of $0.75 \mathrm{mR} /$ week $^{5}$ multiplied by storage time). Fig. 2 indicates that Do definitely increases with storage time in holders and tends to saturate. The speed at which Do approaches saturation and the saturation level depend on light intensity. This fact explains, for example, why Do of chip 2, the latter being located under a copper absorber increases more slowly than does Do of the otherwise identical chip 1. High light intensity incident on the doismeters used for Fig. 2 probably also accounts for the relatively large light produced signal for chip 3 ( $\sim 20 \mathrm{mR}$ after 20 days, whereas the intercept of Fig. 1c suggests that on average dosimeters in homes exhibit Do's saturating near $12 \mathrm{mR}$ ). The results depicted in Fig 2. confirm that under normal conditions (such as would prevail for field dosimeters) the values for Do obtained from extrapolation of the cumulative dosimeter cards $(3,3,12,4 \mathrm{mR}$ for Chips 1-4 respectively) are the proper ones to use. Linearity of plots such as those in Fig. 1 indicate that the values, 3, 3, 12, 4, for chips 1-4 respectively, remain constant for storage times greater than $\sim 6$ weeks. For dosimeters that have been exposed in holders much less than 6 weeks, especially if they have been stored in subdued light, lower values of Do might be more realistic.

\section{4: Variation of Background Radiation}

Values of the background accumulation rate, (D-Do)/t (where $D$ is the measured dose, Do is the value given in section 3.3, appropriate for each chip, and $t$ is the time between annealing and reading) have been evaluated for all dosimeters used in this study. As in the case for routine personnel dosimeters, a small percentage of the results was rejected when glow curve shapes indicated damaged chips or when dosimeters were not returned. 


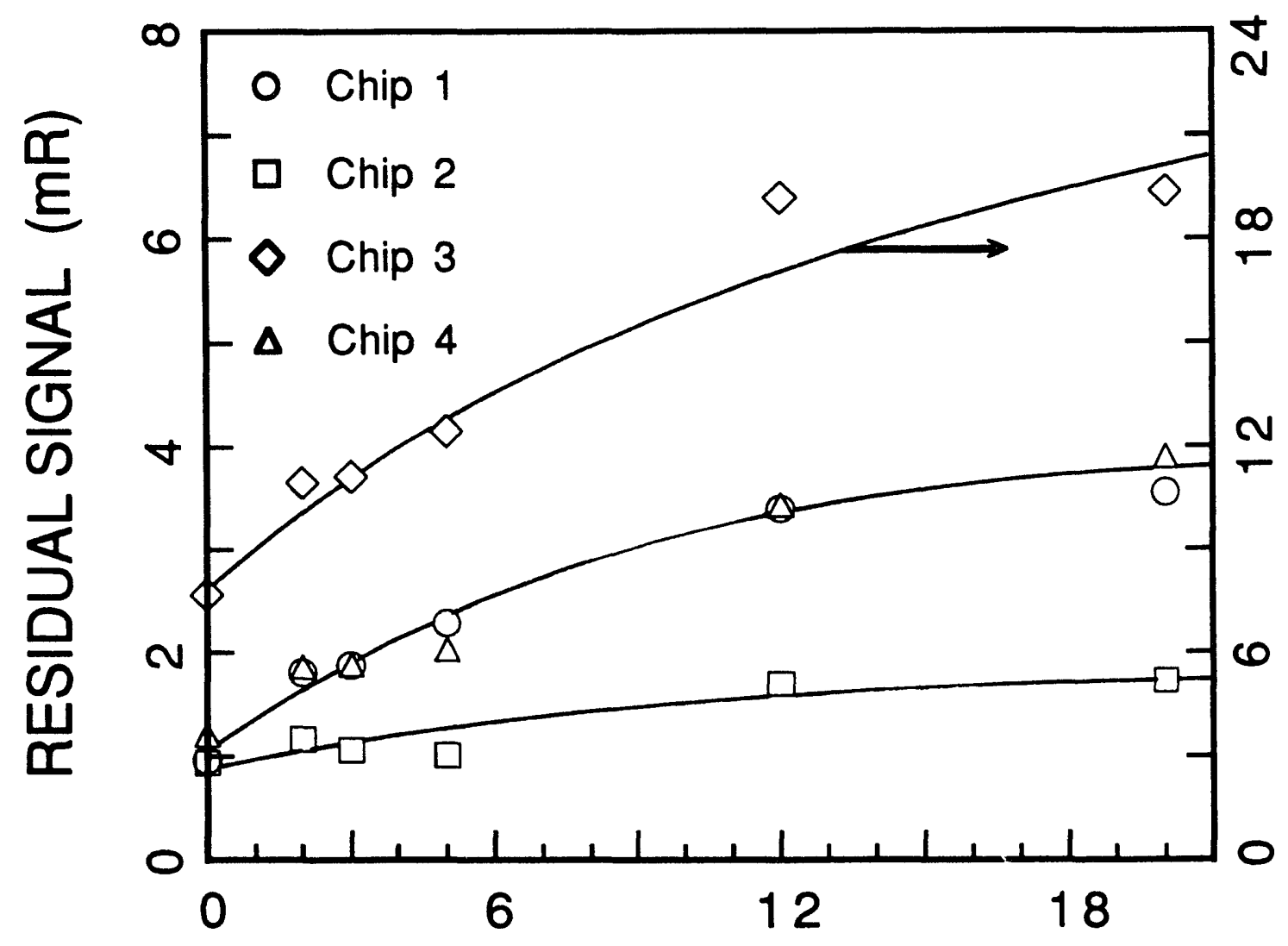

TIME (days)

Fig. 2: Average Residual Response of Encased Dosimeters stored in Room Light. The contribution of actual background gamma radiation (.75 mR/week) has been subtracted from all points. The curves shown are drawn simply to indicate data sets for the different chips. Data for chips 1 and 4 are similar s? that they are indicated by the same curve. For chip \#3 the ordinate scale on the right should be used. 


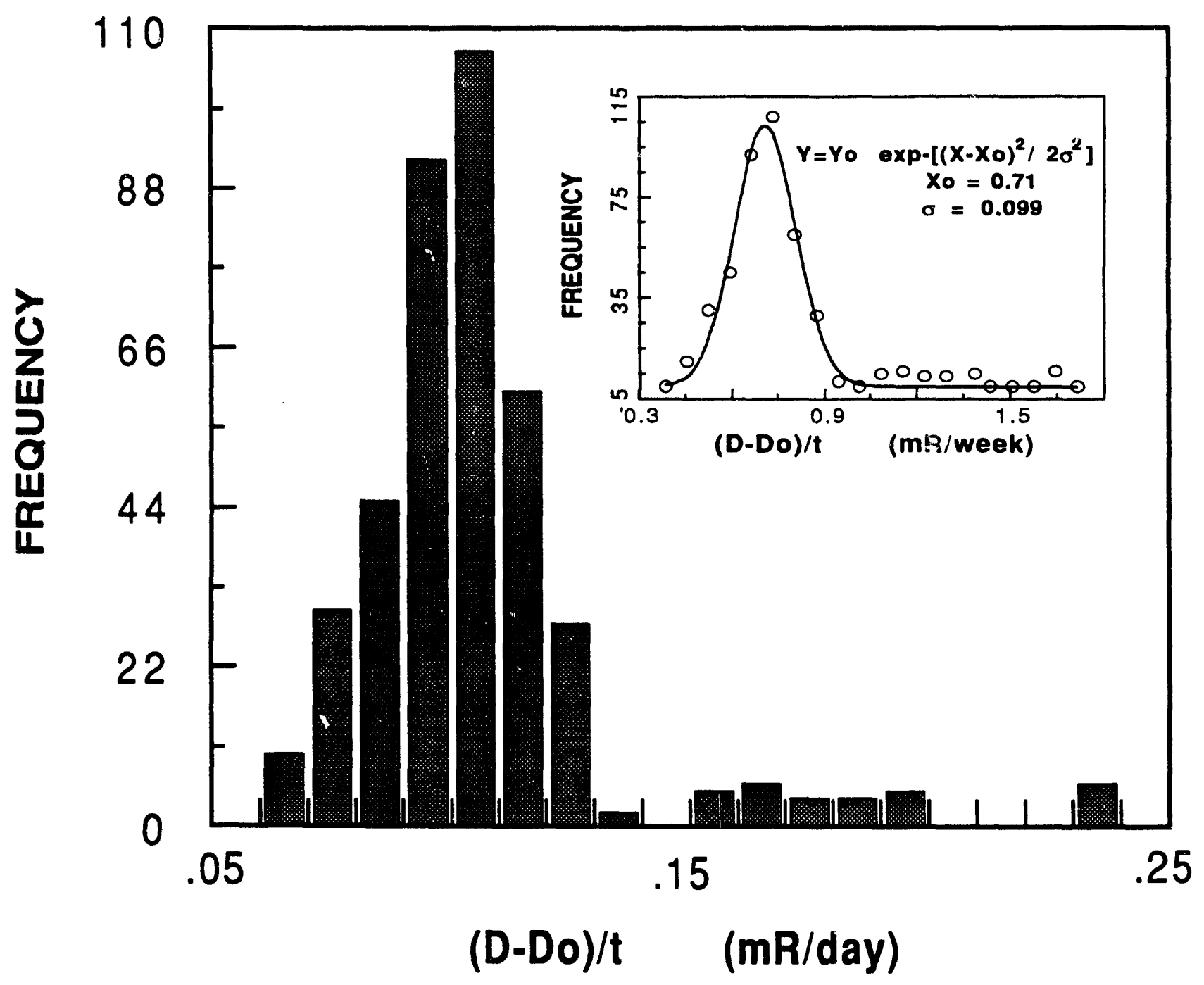

Fig. 3: Distribution of Background Dose Rates as Measured at Many Location For Periods of Approximately Five Months. Data from Chips 1 and 2 are recorded. Thresholdvalues of $3 \mathrm{mR}$ have been subtracted from the measured reader response. The parameters shown have been obtained from a Least Squares fit of the data to the equation as shown in the inset. 
Distributions ( frequency of occurrence plotted vs. dose rate readings) obtained either from approximately 750 "monthly" dosimeters or from a smaller number of dosimeters irradiated for longer times could be well fitted with Gaussian functions except for the preserice of a small number of data points at significantly higher doses than the main distribution. Fig 3 is such a distribution for chips 1 and 2, exposed 4-6 months. The curve shown in the inset is a least squares fit with the parameters indicated. The most probable dose rate (maximum of the distribution) from Fig. 3 is $0.71 \mathrm{mR} /$ week, only slightly less than the slopes for chips 1 and 2 of Fig. 1.

The tail at the high side of the distribution is quite evident in Fig. 3. We have noted that all of these high values are from the same 5 locations; at these the readings wer $\epsilon$ consistently high. If data from these locations were not included in the averages used in Fig. 1, the dose rates obtained from the slopes would be approximately $4 \%$ lower. A $4 \%$ difference in dose rate is not significant in relation to other uncertainties; however, not including the high values greatly decreases the SD and has a significant effect on the $L_{D}$. This effect is discussed in Section 3.5.

It should also be stated that there was no significant difference in average dose rate for dosimeters stored in the vicinity of Paducah versus those stored near Oak Ridge.

To ascertain whether there is any significant seasonal variation in background accumulation, the responses of all "monthly" dosimeter: were normalized for time differences and then averaged over all locations for each month of the year. The results are plotted in Fig 4. Data are presented for all four chips. Do's have not been subtracted. There appears to be no significant variation with season. The only points that appear to be significantly outside the standard errors (indicated by the error bars on the right of the figures) are those for Month 4 (August). During that month the thermoluminescence dosimeter reader was moved to a new building, and although we could find no specific calibration problem on the day the dosimeters for August were read, it is possible that during that period the change in routine contributed to systematic errors lowering the points.

\section{5: Lower Limit of Detection.}

The determination of the lower limit of detection is specified in DOE/EH0027,3 where the $L_{D}$ is calculated from the equation:

$$
L_{D}=\frac{2\left[t_{p} S_{o}+H_{0}{ }^{\prime}\left(t_{p} S_{1} / H_{1}\right)^{2}\right]}{1-\left(t_{p} S_{1} / H_{1}\right)}
$$



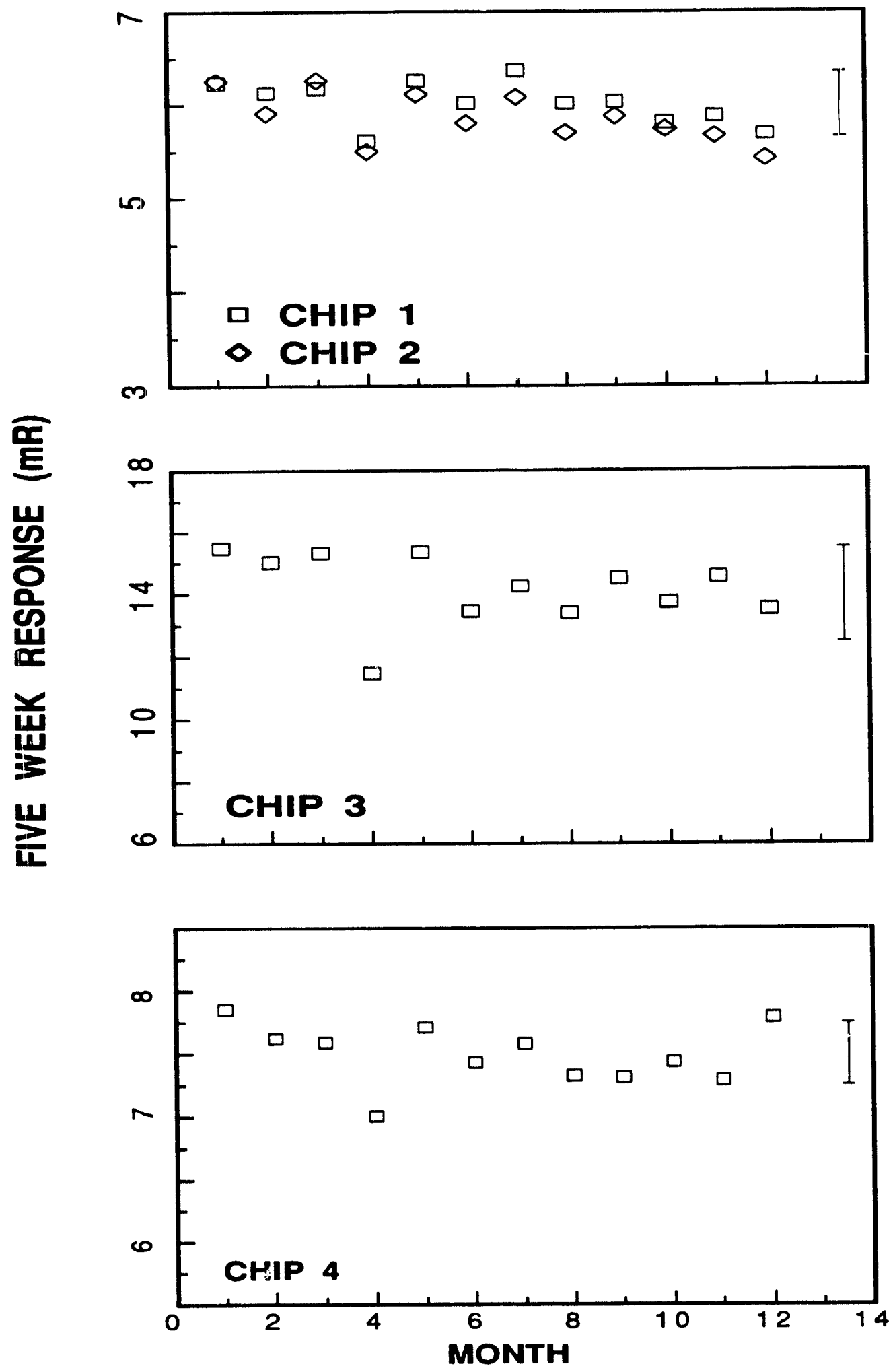

Fig. 4: Average Dosimeter Response Measured Each Month During One Year. Month \# 1 refers to May 1990 and Month \# 12 refers to April, 1991. The error bars at theright of the figures are standard errors calculated from data from approximately 60 to 70 locations. 
In Eq. $1, t_{p}$ is the value of the Student $t$-distribution for $n-1$ degrees of freedom and a probability value of $95 \%$ (For example $t_{p}=1.68$ for $n=52$ ) The values with the subscript 0 are for unirradiated dosimeters while those with the subscript 1 are for irradiated ones. The values $H$ are dose equivalents in rem while $S$ refers to the standard deviation of the values of $H$. It should be pointed out that determination of $H$ and $L_{D}$ not only requires measurement of the response of irradiated and unirradiated dosimeters, but also of invoking the algorithm ${ }^{6}$ that converts the generic units of the card reader to dose equivalent (rem) for different types of radiation.

In Table III are listed calculated values of the $\mathrm{L}_{\mathrm{D}}$ for ${ }^{13^{\prime}} \mathrm{C} \mathrm{C}$ gamma rays and three different beta-ray distributions. It must be pointed out that these calculations invoive a number of choices and assumptions. For example, So in the first term of Eq. 1, the standard deviation of unirradiated dosimeters is assumed to be for a well behaved distribution, due to such effects as measuring error. As Fig. 3 indicates, the present background measurements exhibit a nearly normal distribution for most of the locations, but consistently show much higher values for 5 (of the 70) locations. In Table IV we have tabulated $L_{D}$ values for two cases: (a) background measurements at 53 locations 7,5 of which exhibit dose rates in the tail of the distribution, and (b) background measurements at 48 locations, all of which fall within the main distribution.The differences obviously are large. They will be discussed below in Section 4.4 .

TABLE III: Lower Limit of Detection

\begin{tabular}{|c|c|c|c|c|c|c|}
\hline \multirow{3}{*}{ Type } & \multicolumn{2}{|l|}{ Radiation } & \multicolumn{4}{|c|}{ Lower Limit of Detection (mrem) } \\
\hline & \multirow[t]{2}{*}{ Source } & \multirow[t]{2}{*}{ * } & \multicolumn{2}{|c|}{39 day storage } & \multicolumn{2}{|c|}{156 day storage } \\
\hline & & & all data & WO high & all data & WO high \\
\hline Gamma & Cs & $\mathrm{d}$ & 4.3 & 2.4 & 20.6 & 10.0 \\
\hline Rays & & $\mathbf{s}$ & 10.5 & 6.9 & 33.0 & 23.1 \\
\hline & $\mathrm{Sr}$ & $\mathbf{s}$ & 10.9 & 7.1 & 34.7 & 24.3 \\
\hline Beta & & & & & & \\
\hline \multirow[t]{2}{*}{ Particles } & $\mathrm{Tl}$ & $\mathbf{s}$ & 15.8 & 10.3 & 51.5 & 36.2 \\
\hline & $\mathrm{U}$ & $\mathbf{s}$ & 20.0 & 13.1 & 65.8 & 46.7 \\
\hline
\end{tabular}




\section{DISCUSSION}

\section{1: High Do values for Chip 3.}

The much greater value of Do of chip 3 as compared to the other chips (12 $\mathrm{mR}$ vs. 3 according to the intercepts of Fig. 1) has two sources. Since the chip is thinner, the factor that converts luminescent light output to dose has to be greater by the ratio of chip volumes. Thus instrument noise produces a proportionately larger Do reading for chip 3 . The effect of light leakage which affects primarily the Teflon cover rather than the chip itself ${ }^{4}$ is similarly amplified by the greater conversion factor of chip 3 .

\section{2: Possible Difference in Background Response of the Four Chips.}

The background dose rate as indicated by the slopes of Fig. 1 appears to be somewhat lower when measured by chips 1 and 2 than when measured with the other two chips. The difference between chips 1 and 2 and chip 3 is probably within the experimental uncertainty. However we believe the higher slope indicated for chip 4 is a real effect, although it obviously can not be indicative of any difference in radiation background.This effect is discussed in the following paragraphs. Using the data for chips 1, 2, and 3, and the fact chip 3 is of lower volume and therefore exhibits a higher SD, we propose a values of $0.75 \mathrm{mR} /$ week for the background radiation accumulation rate.

The higher accumulation rate exhibited by chip 4 is probably due to the initial acceptance testing of dosimeter cards ${ }^{8}$, during which chip \#4 sustains considerable local damage as well as some $\mathrm{He}$ and ${ }^{3} \mathrm{H}$ buildup due to the ${ }^{6} \mathrm{Li}(\mathrm{n}, \alpha)^{3} \mathrm{H}$ reaction. Both the modification of the chip material and the fact that ${ }^{3} \mathrm{H}$ is radioactive can influence the apparent background dose rate.

It is well known 9 that heavy irradiation of LiF TLD material produces damage and trapped electrons not all of which anneal out in a subsequent single $\mathrm{read} /$ anneal cycle. As a matter of fact techniques have been developed ${ }^{9}$ for rereading heavily irradiated dosimeters by using ultraviolet light to transfer electrons from these deep, unemptied traps to shallow ones, which then produce luminescence during another read/anneal. In the case of our dosimeters where there is no deliberate ultraviolet light excitation of deep traps, there nevertheless is the likelihood of sunlight penetration of the dosimeter holders and/or thermal excitation promoting a fraction of electrons from the deep to shallow traps during storage and background exposure following the initial neutron acceptance tests. The fact that chip 4 often exhibits a light emission tail at the high temperature end of the anneal 
cycle supports the hypothesis that there are electrons in deep traps. This mechanism may alse account for Do of chip 4 being larger than Do for chips 1 and 2.

Piesch and coworkers ${ }^{10}$ have studied tritium buildup in ${ }^{6} \mathrm{LiF}$ and give a value for the self-irradiation rate of dosimeter chips due to neutron produced ${ }^{3} \mathrm{H}$. From their value and an estimate of the thermal neutron fluence ${ }^{11}$ due to our 50 mrem (moderated Cf spectrum) acceptance test dose we conclude that Tritium self irradiation due to acceptance testing adds a few percent to the normal background accumulation.

\section{3: Reasons for High LLD in Dosimeters Stored for Extended Times.}

As stated earlier (Section 1) the determination of occupational exposure requires the subtraction of background radiation; thus its uncertainty and consequently the $L_{D}$ depends on the uncertainties of both irradiated dosimeter measurements and measurements of background. This fact is reflected in Eq. 1 by the two terms in the numerator, one involving So, the standard deviation (SD) of the background dosimeters, and the other involving S1, the SD of the irradiated ones. In performing the calculations, it became clear that So was by far the major contributor to the $L_{D}$, usually by a factor of 10 to 100 . Since the total absorbed background dose increases with time a dosimeter is in the field the uncertainty (i.e. the SD) of that background dose also increases. This leads to increased $L_{D}$ 's for extended storage times.

\section{4: Lower Limit of Detection to be Used for Personnel Dosimeters.}

In routine personnel dosirnetry at Martin Marietta Energy Systems, dosimeter responses that are lower than the $L_{D}$ are normally reported as zero occupational dose. Thus it is important tha' the assumptions made in determining $L_{D}$ values are applicable to routine use.

The distribution of home background depicted in Fig. 3 and the fact that all the high data come consistently from the same 5 locations would seem to imply that in a population of houses most exhibit background dose rates within a normal distribution, as indicated by the fitted curve, while $\sim 7 \%$ have anomalously high backgrounds. On the assumption that our sample of 70 houses reflects the homes of all workers at the Energy Systems facilities, we have calculated $L_{D}$ values for two cases, using all the background values and only background values that fall within the main part of the distribution. 
If the LDS obtained with all background data (the larger values) are used for routine personnel dosimetry, dosimeters that are stored at the high dose locations, which will produce somewhat elevated readings, will nevertheless be reported as "zero occupational dose". However, dosimeters that are stored in homes with normal background and which have been exposed to a small occupational dose will also be reported as "zero dose".

If the $L_{D} s$ obtained with only the normal distribution of home backgrounds (the smaller values) are used, then small occupational doses have a greater probability of being noted and recorded, but some of the dosimeters from the locations with high background will tend to indicate an "occupational dose" when in reality the dose comes from background.

The conservative choice is clearly to base the minimum reporting level on the lower $L_{D} s$. Since the percentage of anomalously high locations is small, there will not occur a deluge of positive non-occupational values. Moreover, in contrast to the dosimeters used in the present study, which were at their locations for 24 hours each day, personnel dosimeters will be worn or be in a vehicle for at least a third of the day and will most probably be stored in various locations at different times. Thus the chance of accumulating anomalously high background doses is significantly reduced.

\section{5: $L_{D}$ Values for Beta Spectra.}

For shallow dose the $L_{D}$ values are significantly higher for two reasons: First, whereas the conversion factor from generic units $(\mathrm{mR})$ to dose equivalent is approximately 1 for gamma rays it is significantly higher for low energy electrons; thus the related SD values are also higher. Secondly the shallow doses depend upon readings from chip 3 , which, because of its thin construction, gives rise to large errors for low doses such as those received during background measurements.

\section{SUMMARY}

Measurements of background radiation have been performed for periods up to 1 year at 70 locations. The average dose rate is $0.75 \mathrm{mR} /$ week. A distribution of results yields a Gaussian with $\sigma$ of $0.1 \mathrm{mR} /$ week. However the uncertainty in background is not strictly statistical; a few locations yield background radiation rates of almost twice the average. These anomalous locatinns do not significantly affect the value of the mean dose rate; however they significantly increase the standard deviation of the hackground, a 
parameter that has a large influence on the lower limit of detection.

Background radiation accumulation as measured with TLDs does not exhibit any non-linearity; the rate is constant up to a year. However, at short times ( $t$ $<\sim 6$ weeks) the residual dosimeter response, Do, is shown to depend on light leakage through the dosimeter case. This effect adds an uncertainty of approximately 2-3 mR to dose readings which is significant at low doses.

The lower limit of detection depends to a large extent on the radiation background and assumptions made about background exposure of personnel dosimeters. Values for a number of cases have been calculated (Table IV). The $L_{D}$ for high energy gamma rays obtained in a short exposure is $2.4 \mathrm{mrem}$. However, for example, for a depleted uranium beta particle spectrum, and longer elapsed time between dosimeter preparation and measurement $(\sim 22$ weeks), the $L_{D}$ value is 47 mrem. The effect of the non-normal distribution of radiation background at different locations is discussed and its effect on the $L_{D}$ is evaluated. We suggested that data from the high background locations be ignored in determining values of $L_{D}$ to use for routine personnel dosimetry monitoring.

\section{ACKNOWLEDGEMENTS}

This study required the assistance and cooperation of participants too numerous to list. Their efforts are gratef ally acknowledged. Our special thanks go to T. C. Dodd, C.E. Maples, and M. L. Souleyrette, who distributed and collected dosimeters from participants at Paducah, K-25 and Y-12. D. S. Colwell and P. R. Smith annealed and measured the exposed dosimeters. Discussion with and suggestions made by K.L. McMahan were very helpful. 


\section{REFERENCES}

1) The dosimeters used for this study are the same as used for routine personnel monitoring at Martin Marietta Energy Systems facilities. They are Harshaw Model 8801, 4-chip, thermoluminescence dosimeter cards, supplied by Solon Technologies Inc., Solon $\mathrm{OH}, 44139$. For a description see e.g. C.D. Berger \& B.A. Kelly, "Technical Basis for the Centralized External Dosimetry System", Martin Marietta Energy Systems, (1991) (unpublished)

2) A.B. Ahmed, "Measurement of Background Accumulation by the Centralized External Dosimetry Systems Beta-Gamma Dosimeters", CEDS Internal Technical Report, (1987) (unpublished)

3) U.S. Department of Energy Standard for the Performance Testing of Personnel Dosimetry Systems, DOE/EH-0027, (1986)

4) E. Sonder A.B. A.hmed, K.L. McMahan, D.S. Colwell, \& P.R. Smith, "The Effect of Visible Light on Harshaw Model 8801 Thermoluminescent Dosimeters", Technical Memo, ORNL/TM-11651, (1990)

5) from data summarized in Table II and discussed in section 4.2

6) M. Moscovitch, G. Bencke \& B. Wilder, "Dose Calculation Algorithm for the Department of Energy Laboratory Accreditation Program", Report, released 19 June 1989, Engelhard Corp. Harshaw Crystal \& Electronics Products, Solon, Ohio (1989)

7) The 53 location, data from which were used for the $L_{D}$ calculations, are a subset of the 70 homes used for this background study, for which all dosimeters stored for 6.5 weeks or 23 weeks were returned at the correct time and did not exhibit any abnormalities in the glow curves.

8) Procedure 2-1-20, "Quality Acceptance Testing of New TLD Cards", and procedure 2-1-95, "ECC Determination", CEDS Standard Operating Procedures and Quality Assurance Program Manual, ORNL (1991) (unpublished)

9) See for example the review by V.K. Jain, "Thermoluminescence of Lithium Fluoride",Radiation Protection Dosimetry 2, 141, (1982) or B. Ben-Shachar, "Ultraviolet Sensitivity and Photo-Transferred Thermoluminescence of the Harshaw and Panasonic Used TLDs - a Comparison", Appl. Radiation Isot. $\underline{40} 687$, (1989) 
10) E. Piesch, B. Burgkhardt, \& A.M. Sayed, "Activation and Damage Effects in TLD 600 After Neutron Irradiation", Nucl. Instr. \& Methods 157, 179, (1978)

11) E. Casson, "Neutron Energy Spectrum of Moderated Cf Source", private communication, (1991) 
ORNL/TM-11995

\section{INTERNAL DISTRIBUTION}

$\begin{aligned} 1-5 & \text { A. B. Ahmed } \\ 4-18 & \text { R. S. Bogard } \\ 19 & \text { H.M. Butler } \\ 20 & \text { D. S. Colwell } \\ 21 & \text { S. W. Croslin } \\ 22 & \text { E. Dixon } \\ 23-33 & \text { T. C. Dodd } \\ 34 & \text { R. W. Fields, Jr. } \\ 35 & \text { J. B. Hunt } \\ 36 & \text { C. E. Maples } \\ 37 & \text { K. L. McMahan } \\ 38 & \text { G. T. Mei } \\ 39 & \text { L.J. Schwanke }\end{aligned}$

$\begin{aligned} 40 & \text { P.E. Shaver } \\ 41 & \text { C.S. Sims } \\ 42 & \text { P. R. Smith } \\ 43 & \text { D.E. Somers } \\ 44-64 & \text { E. Sonder } \\ 65 & \text { M. L. Souleyrette } \\ 66 & \text { N. A. Teasley } \\ 67 & \text { M. Thein } \\ 68 & \text { Central Research Library } \\ 69-70 & \text { Laboratory Records } \\ 71 & \text { Lab. Records, ORNL-RC } \\ 72 & \text { ORNL Patent Section } \\ 73 & \text { ORNL Y-12 Technical Library } \\ 74 & \text { Document Reference Section }\end{aligned}$

\section{EXTERNAL DISTRIBUTION}

75 Office of Assistant Manager for Energy Research and Deveiopment, Department of Energy, Oak Ridge Operations, P. O. Box 2001, Oak Ridge, TN 37831.

76-85 Office Of Science and Technical Information, P. O. Box 62, Oak Ridge, TN 37831

86 Andy Bassett, DOE-ORO, P. O. Box 2001, Oak Ridge, TN 37831

87 M. M. Thomas, DOE-ORO, P. O. Box 2001, Oak Ridge, TN 37831

88 Tom Jelinek, DOE-ORO, P. O. Box 2001, Oak Ridge, TN 3731

89 R. D. Carlson, U.S. DOE, 785 DOE Place, Idaho Falls, ID, 83402-4149

90 J.J. Fix, Batelle-PNL, Batelle Boulevard, Richland, WA 99352

91 Rod A. Tawil, Solon Technologies, Inc. 6801 Cochran Road, Solon, OH 44139

92 C. F. Wu, Waste Isolation Pilot Plant, P.O. Box 2078, Carlsbad, NM 88221 

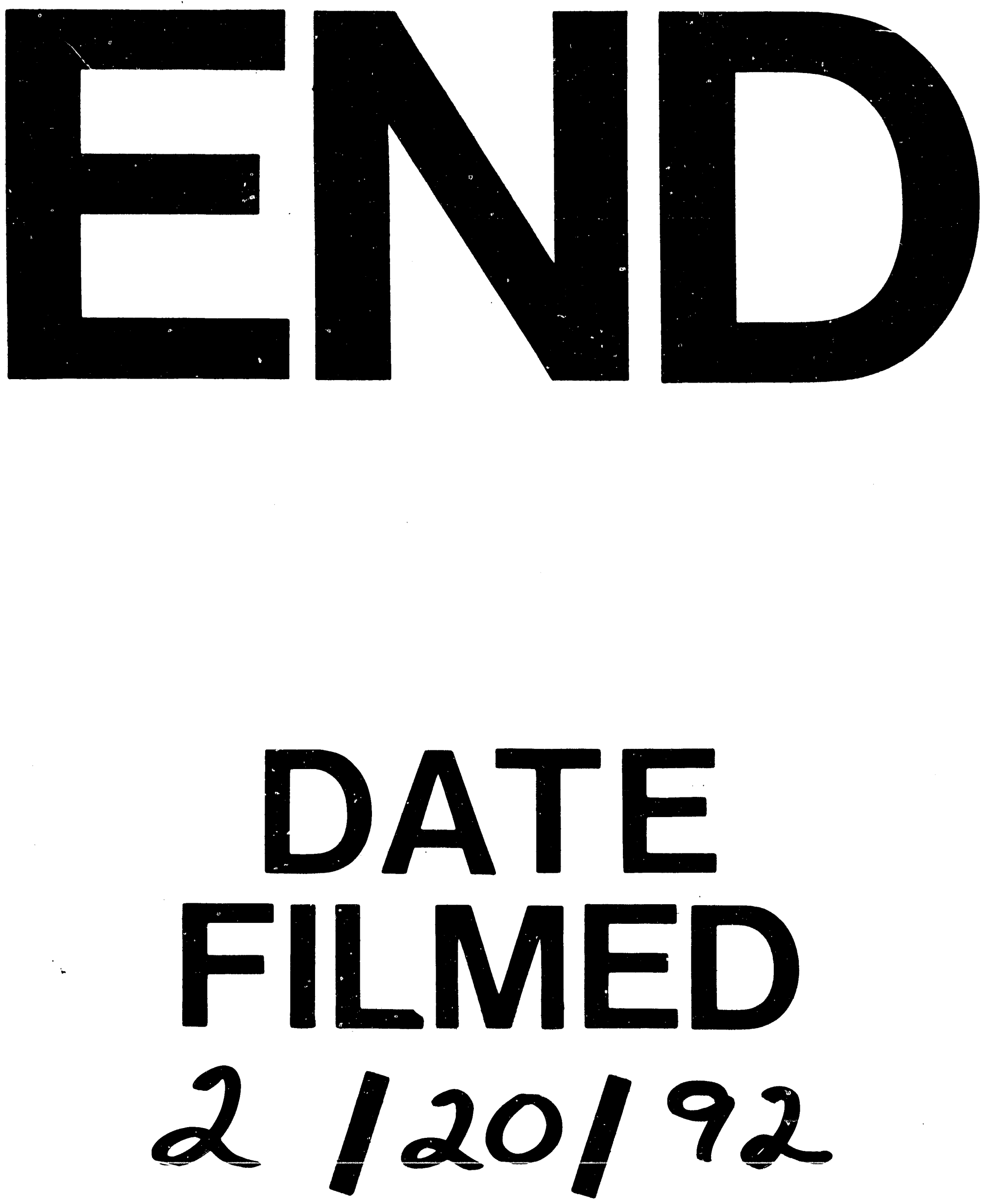

I 
